\title{
Korean parents' perceptions of the challenges and needs on school re-entry during or after childhood and adolescent cancer: a multi-institutional survey by Korean Society of Pediatric Hematology and Oncology
}

Jun Ah Lee, $M D^{1}$, Jae Min Lee, $M D^{2}$, Hyeon Jin Park, MD ${ }^{1}$, Meerim Park, $M D^{1}$, Byung Kiu Park, MD ${ }^{1}$, Hee Young Ju, MD ${ }^{3}, J^{3}$ Yoon Kim, $\mathrm{MD}^{4}$, Sang Kyu Park, $\mathrm{MD}^{5}$, Young Ho Lee, $\mathrm{MD}^{6}$, Ye Jee Shim, $\mathrm{MD}^{7}$, Heung Sik Kim, $\mathrm{MD}^{7}$, Kyung Duk Park, $\mathrm{MD}^{8}$, Yeon-Jung Lim, MD ${ }^{9}$, Hee Won Chueh, MD ${ }^{10}$, Ji Kyoung Park, MD ${ }^{11}$, Soon Ki Kim, MD ${ }^{12}$, Hyoung Soo Choi, MD ${ }^{13}$, Hyo Seop Ahn, $M D^{13}$, Jeong Ok Hah, MD ${ }^{14}$, Hyoung Jin Kang, $M D^{15}$, Hee Young Shin, $M D^{15}$, Mee Jeong Lee, MD ${ }^{16}$

${ }^{1}$ Department of Pediatrics, Center for Pediatric Cancer, National Cancer Center, Goyang, Korea; ${ }^{2}$ Department of Pediatrics, Yeungnam University College of Medicine, Daegu, Korea; ${ }^{3}$ Department of Pediatrics, Samsung Medical Center, Seoul, Korea; ${ }^{4}$ Department of Pediatrics, Kyungpook National University School of Medicine, Daegu, Korea; ${ }^{5}$ Department of Pediatrics, Ulsan University Hospital, University of Ulsan College of Medicine, Ulsan, Korea; ${ }^{6}$ Department of Pediatrics, Hanyang University College of Medicine, Seoul, Korea; ${ }^{7}$ Department of Pediatrics, Keimyung University School of Medicine, Daegu, Korea; ${ }^{8}$ Department of Pediatrics, Chonbuk National University Hospital, Jeonju, Korea; ${ }^{9}$ Department of Pediatrics, Chungnam National University College of Medicine, Daejeon, Korea; ${ }^{10}$ Department of Pediatrics, Dong-A University College of Medicine, Busan, Korea; ${ }^{11}$ Department of Pediatrics, Inje University Busan Paik Hospital, Busan, Korea; ${ }^{12}$ Department of Pediatrics, Inha University College of Medicine, Incheon, Korea; ${ }^{13}$ Department of Pediatrics, Seoul National University Bundang Hospital, Seongnam, Korea; ${ }^{14}$ Department of Pediatrics, Daegu Fatima Hospital, Daegu, Korea; ${ }^{15}$ Department of Pediatrics, Cancer Research Institute, Seoul National University College of Medicine, Seoul, Korea;

${ }^{16}$ Department of Pediatrics, Dankook University College of Medicine, Cheonan, Korea

Background: For children and adolescents with cancer, going back to school is a key milestone in returning to "normal life." Purpose: To identify the support vital for a successful transition, we evaluated the parents' needs and the challenges they face when their children return to school.

Methods: This multi-institutional study was conducted by the Korean Society of Pediatric Hematology and Oncology. The written survey comprised 24 questions and was completed by 210 parents without an interviewer.

Results: Most parents (165 of 206) reported that their children experienced difficulties with physical status $(n=60)$, peer relationships $(n=30)$, academic performance $(n=27)$, emotional/behavioral issues $(\mathrm{n}=11)$, and relationships with teachers $(n=4)$ on reentering school. Parents wanted to be kept informed about and remain involved in their children's school lives and reported good parent-teacher communication (88 of 209, 42.1\%). Parents reported that $83.1 \%$ and $44.9 \%$ of teachers and peers, respectively, displayed an adequate understanding of their children's condition. Most parents (197 of 208) answered that a special program is necessary to facilitate return to school after cancer therapy that offers emotional support $(\mathrm{n}=85)$, facilitates social adaptation $(\mathrm{n}=61)$, and provides tutoring to accelerate catch up $(\mathrm{n}=56)$, and continued health care by hospital outreach and school personnel $(n=50)$. Conclusion: In addition to scholastic aptitude-oriented programs, emotional and psychosocial support is necessary for a successful return to school. Pediatric oncologists should active- ly improve oncology practices to better integrate individualized school plans and educate peers and teachers to improve health literacy to aid them in understanding the needs of children with cancer.

Key words: School re-entry, Childhood cancer, Parents

\section{Key message}

Question: What are the parental needs and challenges when their children return to school after cancer?

Finding: In addition to scholastic aptitude-oriented programs, emotional and psychosocial support is necessary for a successful return to school.

Meaning: Pediatric oncologists should actively engage in improving oncology practices to better integrate individualized school plans and educate peers and teachers to improve health literacy to make them understand the needs of children with cancer.

\section{Introduction}

As the survival of children with cancer has greatly improved, quality of life is becoming an important issue. ${ }^{1)}$ Health status and school life are closely related to short- and long-term quality of life in children who have survived cancer. ${ }^{2)}$ Many authorities address quality of life issues, including education, and encourage rapid return to school..$^{2-5)}$ In Korea, children and adolescents 
with cancer or chronic diseases are provided with special educational programs, such as hospital schools or web-based education.6) Supported and funded by the Ministry of Education and local governments, those programs cover education courses from elementary to high school during long-term absence from school. $\left.{ }^{6}\right)$ It is widely known that children and adolescents with cancer or those who have survived the disease face challenges when they return to school, such as increased anxiety, impaired social competence, fewer friends, and poor self-esteem. ${ }^{2,7)}$ Childhood cancer survivors in Korea reported that they do not have enough time to study, or are not physically capable of catching up with their schoolwork, and felt lacking social skills. ${ }^{8}{ }^{8}$ Frequently suggested causes are long-term school absence and the neurocognitive and psychosocial effects of cancer treatments. ${ }^{2,3,7)}$ Moreover, the parents of children and adolescents with cancer are burdened with the dual duties of "traditional parenting" and being "communicators." They are often caught between the health care and educational systems, communicating pertinent information regarding medical needs to the school, and school concerns to the medical team.

Studies have investigated Korean childhood cancer survivors' school experiences. ${ }^{8-12)}$ Korean society and culture are different from Western societies, with prevalent social prejudice, discriminatory attitudes toward cancer patients, and highly competitive academic environments. ${ }^{8,913)}$ Such social environments could pose more challenges for both children and parents on the former's return to school. Korean pediatric oncologists are taking leading roles in hospital school programs and have come together with children and their parents against the challenges at the time of returning to school. Recently, a growing need has been felt for a support program that can successfully bridge the gap between hospital school and "real" school., ${ }^{214,15)}$ To facilitate the establishment of such a program, we aimed to assess parental perceptions of the challenges faced by their children when they return to school during or after cancer treatment.

Table 1. Parents' demographic characteristics

\begin{tabular}{lc}
\hline Characteristic & No. (\%) \\
\hline Relationship & \\
Mother & $177(84.3)$ \\
Father & $32(15.2)$ \\
Grandmother & $1(0.5)$ \\
Age & \\
30 s & $16(7.6)$ \\
40 s & $153(72.9)$ \\
50 s & $40(19)$ \\
Unknown & $1(0.5)$ \\
Highest level of education & \\
Middle school & $6(2.9)$ \\
High school & $82(39)$ \\
College/university & $96(45.7)$ \\
Postgraduate & $17(8.1)$ \\
Unknown & $9(4.3)$ \\
\hline
\end{tabular}

\section{Methods}

\section{Participants}

This study was conducted by the Korean Society of Pediatric Hematology and Oncology, funded by the Korea Childhood Leukemia Foundation. Between July 22, 2015 and December 31, 2016, parents of children with cancer who received treatment at the 15 participating hospitals were invited to this survey if their child was (1) either on cancer treatment or had completed all treatment; (2) age $\geq 9$ years, and (3) had been back to school for more than 1 year. The number of participants was 210 , with majority of them being mothers in their 40's and highly-educated (Table 1).

\section{Data collection and analysis}

This study was approved by the Institutional Review Boards of all participating institutions, and parents provided written informed consent. The survey was composed of 24 objective questions, and some included multiple choices (Table 2). It was completed by participating parents without an interviewer. As this was a descriptive study, counts or percentages, reflecting the number (or proportion) of participants who reported experiencing a particular theme, were used to minimize bias. Not all participants answered every question, and for such cases, counts representing the number of parents who responded to a particular question were considered as estimates of the number of parents who might have experienced these issues.

\section{Results}

\section{Parental concerns before return to school}

While most parents $(n=156,74.3 \%)$ reported that their children returned to school immediately or the next semester, 54 parents (25.7\%) replied that the return was at least 1 year after intensive therapy or completing treatment. The reasons for the delay in the return to school were physical symptoms or sequelae after therapy $(n=34)$, parental concerns about school life $(n=24)$, children's fear about school life $(n=10)$, and the need to catch up $(n=6)$. At the time of returning to school, most parents (208 of 210) responded that they were worried about their children's school life and some (46 of 208) had more than one concern (Fig. 1). When it came to privacy regarding their children's condition, opinions varied considerably among parents. Most parents $(n=149)$ were open to some information being shared within the school community, with 60 parents willing to have more information given to those closest to their children. However, 59 parents wanted privacy about their children's cancer history. On their children's return to school, 161 parents asked school authorities for special consideration, such as limiting sports activities $(\mathrm{n}=146)$, flexibility in attending classes $(n=40)$, and reducing the burden of homework $(n=8)$ or exams $(n=5)$. However, 49 responded that they did not ask for any special consideration related to school life. 

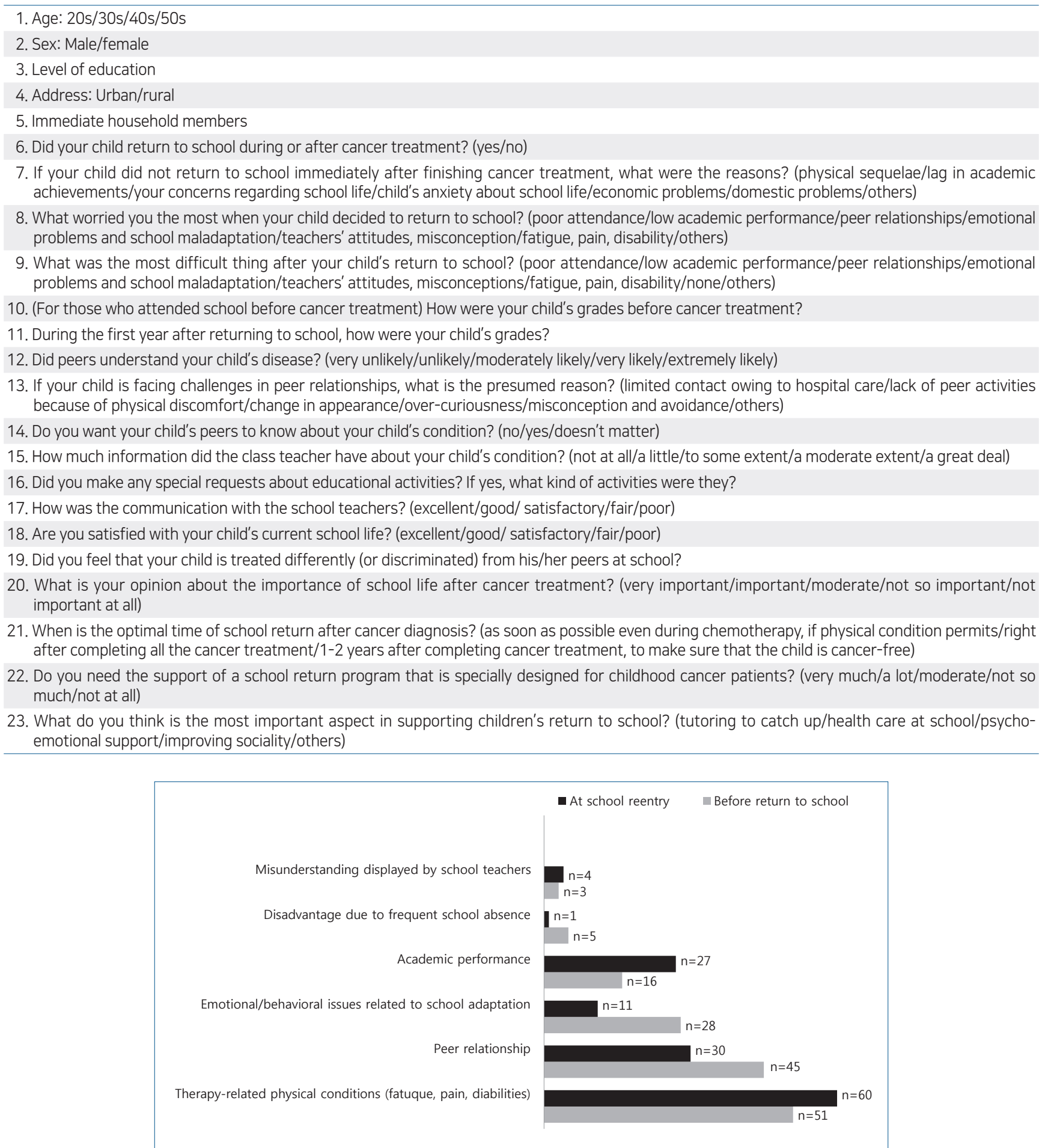

Fig. 1. Parental concerns about and challenges experienced on school re-entry.

\section{Perceived challenges on returning to school}

When their children returned to school, most parents reported that they were satisfied with the current school education. By grading satisfaction levels from 1 to $5(1=$ poor, $2=$ fair, $3=$ satisfactory, $4=$ good, and $5=$ excellent), the distribution reported by 204 parents was: $1(\mathrm{n}=4,2.0 \%), 2(\mathrm{n}=18,8.8 \%), 3(\mathrm{n}=84$, $41.2 \%), 4(\mathrm{n}=64,31.4 \%)$, and $5(\mathrm{n}=34,16.6 \%)$. While $20 \%$ of the parents (41 of 206) reported that their children did not experience any difficulties, most (165 of 206) reported that they did. Some (28 of 206) faced more than one challenge (Fig. 1). Parents were asked about their children's academic performance levels, using scores from 1 to $5(1=$ very poor, $2=$ poor, $3=$ fair, $4=$ good, and $5=$ excellent). The distribution of precancer academic performance levels reported by 161 parents was: $1(\mathrm{n}=4$, 2.5\%), $2(\mathrm{n}=12,7.5 \%), 3(\mathrm{n}=60,37.3 \%), 4(\mathrm{n}=50,31.0 \%)$, and $5(\mathrm{n}=35,21.7 \%)$. The distribution of academic perfor- 


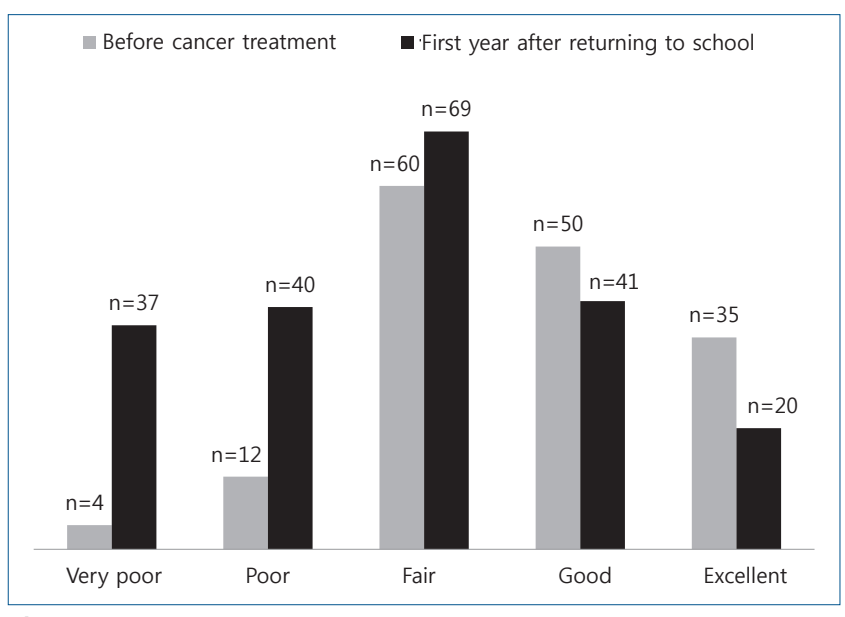

Fig. 2. Parental perceptions of their children's academic performance levels.

mance levels during the first year after returning to school as reported by 207 parents was: $1(\mathrm{n}=37,17.9 \%), 2(\mathrm{n}=40,19.3$ $\%), 3(\mathrm{n}=69,33.3 \%), 4(\mathrm{n}=41,19.8 \%)$, and $5(\mathrm{n}=20,9.7 \%)$ (Fig. 2). After their children's return to school, 86 parents (42.8 $\%)$ did not perceive him/her as having any difficulties in peer relationships. However, 115 (57.2\%) described their children as having difficulties integrating within their peer groups. The presumed causes were frequent school absence $(n=48)$, limited physical activities $(n=35)$, changed physical appearance $(n=23)$, overcurious friends $(\mathrm{n}=8)$, and evasion by peers owing to misunderstanding about cancer $(n=12)$.

\section{Need for a school return program}

After cancer therapy, parents want to be kept informed about and remain involved in their children's school life. Among the 209 parents who answered the question about the parent-teacher relationship, 88 (42.1\%) reported good parent-teacher communication. By grading from 1 to 5 (1=poor, $2=$ fair, $3=$ satisfactory, $4=$ good, and $5=$ excellent), the distribution of communication levels was: $1(\mathrm{n}=4,1.9 \%), 2(\mathrm{n}=17,8.1 \%), 3(\mathrm{n}=$ $100,47.8 \%), 4(\mathrm{n}=52,24.9 \%)$, and $5(\mathrm{n}=36,17.2 \%)$.

Generally, parents perceived their children's schools to be supportive. Regarding peers' understanding of their children's condition, the distribution was: very poor $(\mathrm{n}=49,23.8 \%)$, poor $(\mathrm{n}=42,20.4 \%)$, fair $(\mathrm{n}=78,37.9 \%)$, good $(\mathrm{n}=21,10.2 \%)$, and excellent $(n=16,7.8 \%)$. When it came to teachers, the distribution of parents' perceptions of their understanding level was: very poor $(n=15,7.2 \%)$, poor $(n=20,9.7 \%)$, fair $(n=64$, $30.9 \%)$, good $(n=48,23.2 \%)$, and excellent $(n=60,29.0 \%)$. Most parents (197 of 208) answered that special programs are necessary for children returning to school after cancer. They wanted school return programs to offer multiple services, including emotional support $(\mathrm{n}=85)$, improving sociality for school adaptation ( $\mathrm{n}=61)$, tutoring to accelerate catch up $(\mathrm{n}=56)$, and continued health care by hospital outreach personnel and the school $(n=50)$.

\section{Discussion}

This study is the largest case series in Asia, surveying 210 parents of children who returned to school during or after cancer therapy. Many studies on school return after cancer have been conducted by psychologist, social workers, school teachers, or nurses. ${ }^{5,8,9,14,15,16)}$ However, this survey was initiated by pediatric oncologists, who can improve clinical practices to better integrate individualized education plans and educate peers and teachers to improve health literacy, helping them understand the needs of children with cancer that go beyond the disease. We found that while Korean parents perceive their children's return to school as satisfactory, they want a professional program engaging a wider range of personnel, such as psychologists or social workers, for better emotional or psychosocial support.

Most parents answered that upon their children's return after cancer therapy, schools were supportive. For a successful return to school, hospital school communication is necessary, with special focus on providing information about the impact of cancer and treatment on a child's school life. ${ }^{2,16-18)}$ Most of the parents participating in this survey were open to some information being shared within the school community. Many parents reported that their communication with teachers was good. Most parents (83.1\%) perceived teachers as having a good understanding about their children's condition, and $55.9 \%$ of parents perceived that school peers had a good level of understanding about cancer. The $28 \%$ difference in understanding levels between teachers and peers suggest that information regarding a child suffering from cancer is largely communicated between teachers and parents. Or, peers could not have fully understood the impact of the cancer and its treatment because of their immature intellectual abilities. To facilitate better communication between children/families, peers, and teachers, school visits by hospital personnel to educate peers and teachers might be helpful.2,16,17)

We observed that parents' attitudes toward their children's academic achievement changed after their return to school. In our survey, $7.7 \%$ of parents (16 of 208) answered that they were concerned about academic performance before the return to school. When asked about the professional school return program, $27 \%$ of parents (56 of 208) replied that academic support to facilitate catching up on what has been missed is the most important element. Generally, parents are more concerned about academic performance than their children. ${ }^{19)}$ During cancer therapy, academic success becomes a lower priority compared with the child's physical health, psychological adjustment, and overall well-being. As for school, many parents are primarily concerned with their children's overall educational experience, placing less emphasis on academic attainment. However, on their children's return to school after cancer, parents realize that poor educational attainment negatively impacts long-term quality of life and employment opportunities. ${ }^{20)}$ Survivors of childhood cancer report difficulties in reading, language, and arithmetic skills. ${ }^{19)}$ Learning difficulties are a direct result of cancer therapy, such as intensive chemotherapy or brain damage from surgery or 
radiotherapy. ${ }^{21)}$ In the majority of children with cancer, frequent or extended absenteeism from school results in poor attainment of foundational knowledge and impedes comprehension of higher-level knowledge when they return to school.,18) During long-term absenteeism from school, Korean children and adolescents with cancer continue their educational attainment either by attending hospital schools or through video lectures. ${ }^{6}$ In Korea, many students take private tutoring lessons aside from school to improve academic achievement because parents tend to feel that individualized academic support (i.e., tutoring) is necessary for their children to adjust to the competitive academic environment. ${ }^{9)}$ For a child returning to school after cancer therapy, a professional program that can bridge the gap between hospital school programs and real school is necessary. ${ }^{2,16-18)}$ The current hospital school programs are aimed at helping children keep up with the regular Korean curriculum. ${ }^{6}$ Although they include various subjects, such as music or arts, they are focused on the acquisition of knowledge and improvement of scholastic aptitude. This is contrary to what parents' desire; their responses indicate that emotional or psychosocial support is what is necessary for a successful return to school. The current hospital schools and video lecture system involve three parties, that is, childrenparents, medical personnel, and school authorities. This needs to be further developed into a school return program, engaging a wider range of personnel, such as psychologists or social workers.

Our study has several limitations. First, differences in challenges and needs according to cancer type and school grades were not analyzed, since the survey did not include questions regarding the age, type of cancer, school grade (elementary or middle) at cancer diagnosis. Second, a selection bias might exist regarding the parents who answered the questionnaire. The 210 parents were only a small fraction of the parents of children with cancer and the majority was high school/college graduates who lived in the city area.

In conclusion, Korean parents perceived their children's schools as supportive and their school life as satisfactory, despite some challenges on returning to school during or after cancer therapy. Parents wanted emotional or psychosocial support to be added to the current educational supporting systems (hospital schools or video lecture programs) for a successful return to school. For pediatric oncologists, the areas of potential intervention identified through this study are (1) improvement in pediatric oncology practices to better integrate individualized education plans and (2) education for peers and teachers to improve health literacy to make them understand the needs of children with cancer that go beyond the disease.

\section{Conflicts of interest}

No potential conflict of interest relevant to this article was reported.

\section{Acknowledgments}

This study was supported by a grant from Korea Childhood Leukemia Foundation in 2016.

\section{References}

1. Greenzang KA, Cronin AM, Mack JW. Parental preparedness for late effects and long-term quality of life in survivors of childhood cancer. Cancer 2016;122:2587-94.

2. Thompson AL, Christiansen HL, Elam M, Hoag J, Irwin MK, Pao M, et al. Academic continuity and school reentry support as a standard of care in pediatric oncology. Pediatr Blood Cancer 2015;62 Suppl 5:S805-17.

3. McLoone JK, Wakefield CE, Butow P, Fleming C, Cohn RJ. Returning to school after adolescent cancer: a qualitative examination of australian survivors' and their families' perspectives. J Adolesc Young Adult Oncol 2011;1:87-94.

4. Masera G, Jankovic M, Deasy-Spinetta P, Adamoli L, Ben Arush MW, Challinor J, et al. SIOP Working Committee on Psychosocial Issues in Pediatric Oncology: guidelines for school/education. Med Pediatr Oncol 1995;25:429-30.

5. Moore JB, Kaffenberger C, Goldberg P, Kyeung Mi Oh, Hudspeth R. School reentry for children with cancer: perceptions of nurses, school personnel, and parents. J Pediatr Oncol Nurs 2009;26:86-99.

6. Korean Ministry of Education. Education support system for students with health impairments. Sejong (Korea): Korean Ministry of Education, 2005.

7. French AE, Tsangaris E, Barrera M, Guger S, Brown R, Urbach S, et al. School attendance in childhood cancer survivors and their siblings. J Pediatr 2013;162:160-5.

8. Yi J, Kim MA, Hong JS, Akter J. Childhood cancer survivors' experiences in school re-entry in South Korea: focusing on academic problems and peer victimization. Child Youth Serv Rev 2016;67:263-9.

9. Kim MA, Yi JH. Childhood cancer survivor's services needs for the better quality of life. J Korean Acad Child Health Nurs 2012;18:19-28.

10. Lee Y. The effects of school re-entry support program in the hospital school on the self-perception of children with cancer. Disabil Soc Welf 2008;1:111-38.

11. Nam SI, Choi KH. School reintegration, adjustment difficulties, and services for childhood cancer survivors. Korean J Soc Welf Res 2013;38: 181-215.

12. Yi J, Kim MA, Sang J. Worries of childhood cancer survivors in young adulthood. Eur J Oncol Nurs 2016;21:113-9.

13. Lee $S$, Shouse RC. The impact of prestige orientation on shadow education in South Korea. Sociology of Education 2011;84:212-24.

14. Dumas A, Cailbault I, Perrey C, Oberlin O, De Vathaire F, Amiel P. Educational trajectories after childhood cancer: When illness experience matters. Soc Sci Med 2015;135:67-74.

15. Irwin MK, Elam MP, Merianos AL. Coordination of care between health and education systems for patients with a hematologic or oncologic diagnosis: a time study analysis. J Pediatr Nurs 2015;30:244-53.

16. Bruce BS, Newcombe J, Chapman A. School liaison program for children with brain tumors. J Pediatr Oncol Nurs 2012;29:45-54.

17. Grandinette S. Supporting students with brain tumors in obtaining school intervention services: the clinician's role from an educator's perspective. J Pediatr Rehabil Med 2014;7:307-21.

18. McLoone JK, Wakefield CE, Cohn RJ. Childhood cancer survivors' school (re)entry: Australian parents' perceptions. Eur J Cancer Care (Engl) 2013;22:484-92.

19. Yamamoto Y, Holloway SD. Parental expectations and children's academic performance in sociocultural context. Educ Psychol Rev 2010; 22:189-214.

20. Dumas A, Berger C, Auquier P, Michel G, Fresneau B, Allodji RS, et al. Educational and occupational outcomes of childhood cancer survivors 30 years after diagnosis: a French cohort study. Br J Cancer 2016;114:10608.

21. Kurt BA, Armstrong GT, Cash DK, Krasin MJ, Morris EB, Spunt SL, Robison LL, Hudson MM. Primary care management of the childhood cancer survivor. J Pediatr 2008;152:458-66. 